\title{
Relation of Neck Circumference to Central Obesity and Overweight in Patients with Type 2 Diabetes Mellitus Presenting to a Tertiary Center
}

\author{
Ishwor Sharma', Sanjay K Gupta², Kiran Niraula ${ }^{3}$ \\ 1Department of Nephrology, University at Buffalo, New York, United States of America, ${ }^{2}$ Department of General \\ Practice and Emergency Medicine, Maharajgunj Medical Campus, Tribhuvan University Teaching Hospital, Nepal, \\ ${ }^{3}$ Department of Neurosurgery, ADK Hospital, Maldives.
}

\section{Corresponding author:}

Ishwor Sharma, MD

Department of Nephrology, University at Buffalo, New York, United States of America

Email: ishwor093@yahoo.com

Submitted : Aug 19, 2020

Accepted : Nov 4, 2020

\begin{abstract}
Introduction

Overweight and obesity with their surrogate anthropometric markers like body mass index (BMI), waist circumference (WC) and waist hip ratio (WHR) have been shown to be strongly associated with Type 2 diabetes mellitus. Neck circumference (NC) though less used can be an equally effective alternative to diagnose overweight and obesity in patients with Type 2 diabetes mellitus in a resource limited setting.

\section{Methods}

Patients who had Type 2 Diabetes Mellitus for 5 years or more and above 35 years underwent simple random sampling. Weight, height, WC and NC were measured. BMI was calculated and patients were graded into overweight and obesity based on the Asian cutoffs for BMI and abdominal obesity.

\section{Results}

Among 100 patients enrolled in this study, 45\% were men and the mean age was 53.05. Mean neck circumference was $36.55 \pm 1.28 \mathrm{~cm}$ and $35.27 \pm 1.78 \mathrm{~cm}$ for male and female respectively. NC was positively correlated with WC and BMI in both men and women $(p<0.001)$. In the ROC curves, NC presented the largest area under the curve (AUC) for overweight in males $(p<0.001)$, while NC presented a large AUC for central obesity in both genders. Furthermore, the cut off value of neck circumference for overweight was $35.6 \mathrm{~cm}$ in males vs $35.2 \mathrm{~cm}$ in females and for central obesity was $36.75 \mathrm{~cm}$ in males vs $34.75 \mathrm{~cm}$ in females.
\end{abstract}

\section{Conclusion}

Neck circumference was positively associated with overweight and central obesity in patients with type 2 diabetes mellitus.

\section{Keywords}

Anthropometric measure, diabetes mellitus, neck circumference, obesity 


\section{INTRODUCTION}

$\mathrm{O}$ verweight and obesity has increasingly become a global epidemic. According to WHO (2020), obesity in the world has nearly tripled since 1975. More than 1.9 billion adults were overweight in the year 2016 and over 650 million were obese. ${ }^{1}$ Overweight and its surrogate anthropometric markers have been shown to be strongly associated with increased incidence of Type 2 diabetes mellitus (DM) which is one of the components of metabolic syndrome and cardiovascular risk factors. The surrogate markers of obesity, traditionally used in clinical medicine are body mass index (BMI), waist circumference (WC), and waist hip ratio. Other less commonly used ones are subscapular to triceps skinfold ratio, abdominal sagittal diameter and neck circumference. ${ }^{2}$

Neck circumference (NC) could be a reliable, easy and quick screening measure that can be used, among various other methods, to identify overweight and obese patients. ${ }^{2}$ It can be used as an indirect measure to screen the metabolic syndrome and cardiovascular risk factor like Type 2 DM. ${ }^{2}$ Visceral adipose tissue (VAT) has long been recognized as fat deposit that is pathogenic, leading to increased susceptibility to ischemic heart disease and arterial hypertension. ${ }^{3}$ VAT accounts for only modest correlations between parameters of metabolic syndrome suggesting that deposits of fat in other parts of the body like subcutaneous fat in the neck measured as neck circumference can be used as an alternative way of accessing central obesity. Therefore, neck circumference is taken as an index of upper body subcutaneous adipose tissue distribution and central obesity. Upper body obesity is associated more with glucose intolerance, hyperinsulinemia, diabetes, hypertriglyceridemia, and gout compared to lower body obesity. Study in Nepalese population regarding whether neck circumference can solely be used as an indicator of central obesity is lacking. This prompted us to conduct a study in a tertiary center in Kathmandu to see their correlation.

\section{METHODS}

A cross sectional study with simple random sampling was conducted among patients visiting the department of Internal Medicine at Tribhuvan University Teaching Hospital (TUTH) in Kathmandu, Nepal for two years from September 2011 to September 2013. Patients diagnosed to have type 2 DM for at least 5 years and $>35$ years of age were enrolled during the study period. The main pathophysiology of type 2 DM and Obesity is insulin resistance. Therefore, we chose people with type 2 DM rather than the general population. Total number of patients enrolled in the study was 100. Verbal informed consent was taken from all the participants. Patients with severe disabilities, hepatic failure, renal failure, goitre and those on steroid therapy were excluded from our study as they could act as potential cofounding factors.

To define central obesity, we used the consensus guideline for Asian Indians for abdominal obesity (Table 1) with a waist circumference cut-off of $\geq 90$ $\mathrm{cm}$ in men and $\geq 80 \mathrm{~cm}$ in female. Measurements of neck circumference and waist circumference were taken. Neck circumference was measured with head erect and eyes facing forward, horizontally at the mid-neck height, between the mid cervical spine to mid anterior neck, to within $1 \mathrm{~mm}$. In men with a laryngeal prominence, it was measured just below the prominence. Waist circumference (WC) was measured at the level midway between the lower rib margin and the iliac crest with the patient standing at the end of gentle expiration. Weight was measured without heavy clothing and without shoes, after emptying of bladder, using an analogue scale. Height was measured without shoes, with stadiometer. BMI was calculated by dividing weight (kilogram) with the square of height (meter). ${ }^{4}$

The collected data were entered in the Excel sheet; the quality and consistency of the data were checked through the SPSS program for Windows (version 17.0). A $p$ value $<0.05$ was considered statistically significant. Data were reported as mean \pm standard deviation. Spearman correlation

Table 1. Cut-offs of obesity and abdominal obesity for Asian Indians vs international criteria

\begin{tabular}{|c|c|c|}
\hline Variable & $\begin{array}{c}\text { Consensus guidelines for } \\
\text { Asian Indians }{ }^{\mathrm{a}}\end{array}$ & $\begin{array}{c}\text { Prevalent International } \\
\text { Criteria }\end{array}$ \\
\hline Generalized obesity (BMI cut-offs in kg/m²) & $\begin{array}{l}\text { Normal: } 18.0-22.9 \\
\text { Overweight: } 23.0-24.9 \\
\text { Obesity: } \geq 25\end{array}$ & $\begin{array}{l}\text { Normal: } 18.5-24.9^{b} \\
\text { Overweight: } 25.0-29.9^{b} \\
\text { Obesity: } \geq 30^{b}\end{array}$ \\
\hline Abdominal obesity (Waist circumference cut-offs in cm) & $\begin{array}{l}\text { Men: } \geq 90^{c} \\
\text { Women: } \geq 80^{\circ}\end{array}$ & $\begin{array}{l}\text { Men: } \geq 102^{d} \\
\text { Women: } \geq 88^{d}\end{array}$ \\
\hline
\end{tabular}

Notes: ${ }^{a}$ From consensus guidelines for Asian Indians; ${ }^{b}$ According to World Health Organization guidelines; ${ }^{c}$ Both as per Consensus Guidelines for Asian Indians and International Diabetes Federation; 'According to Modified National Cholesterol Education Program, Adult Treatment Panel III guidelines. ${ }^{1,5-11}$ 
Table 2. Characteristics of the study participants $(n=100)$

\begin{tabular}{lccc}
\hline Parameters & $\begin{array}{c}\text { Male } \\
(\mathrm{n}=45)\end{array}$ & $\begin{array}{c}\text { Female } \\
(\mathrm{n}=55)\end{array}$ & -value \\
\hline Age (years) & $56.07 \pm 10.86$ & $50.58 \pm 11.72$ & 0.01 \\
Weight $(\mathrm{kg})$ & $67.26 \pm 8.57$ & $55.61 \pm 9.00$ & $<0.001$ \\
Height $(\mathrm{cm})$ & $164.33 \pm 5.65$ & $156.94 \pm 5.87$ & $<0.001$ \\
BMI $\left(\mathrm{kg} / \mathrm{m}^{2}\right)$ & $24.84 \pm 2.41$ & $22.58 \pm 3.63$ & $<0.001$ \\
WC $(\mathrm{cm})$ & $89.38 \pm 4.48$ & $84.33 \pm 5.76$ & $<0.001$ \\
NC $(\mathrm{cm})$ & $36.55 \pm 1.28$ & $35.27 \pm 1.78$ & $<0.001$ \\
\hline
\end{tabular}

was performed to assess the association between neck circumference and certain risk factors like BMI and WC. Pearson correlation was calculated to see the association between $\mathrm{BMI}$ and age. Receiver operating characteristic curves (ROC) were constructed to evaluate the relationship of neck circumference to central obesity and overweight quantified as waist circumference and BMI for Asian Indians respectively (Table 1). The cut off value of neck circumference for determining overweight and obese subjects were identified by taking the value of neck circumference which had highest sensitivity and specificity.

\section{RESULTS}

The study sample consisted of 100 patients with 55 female and 45 male patients. The mean age of the study population was $53.05 \pm 11.61$ years. The mean age of the male population included in the study was higher compared to the female population ( $56.07 \pm 10.86$ vs $50.58 \pm 11.72$ years). The main characteristic of the study population is presented in Table 2. The mean fasting blood sugar level was $150.71 \pm 62.46$, post-prandial blood sugar level was $229.40 \pm 101.3$ and $\mathrm{HbA} 1 \mathrm{c}$ was $8.8 \pm 2.5$. We did not take into account the treatment modalities as it was beyond the scope of our study.

Using the Asian cut off values for BMI (Table 1), among the male patients in the study, $33 \%$ were overweight and $49 \%$ were obese while $18 \%$ had

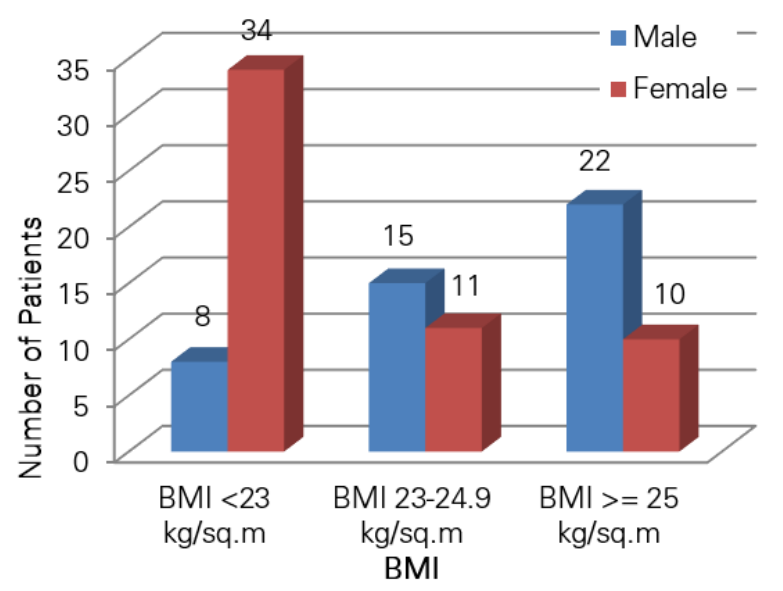

Fig 1. Distribution of patients based on BMI

normal BMI. However, the findings were different in female population with a major bulk falling under the normal BMI category, $20 \%$ being overweight and the rest $18 \%$ being obese (Figure 1 ).

There was a weak correlation between $\mathrm{BMI}$ and age (Pearson correlation coefficient 0.013, $p=0.90$ ). Therefore, there was no significant change of BMI with age of patient. To see the association between neck circumference with central obesity and overweight we checked spearman correlation of NC with WC and BMI in our study. WC was taken as a quantitative measure of central obesity and BMI was taken as a quantitative measure of overweight.

There was strong positive correlation of NC with $\mathrm{BMI}$ and waist circumference in this study. The correlation coefficient between $\mathrm{NC}$ and $\mathrm{BMI}$ was 0.629 in males and 0.655 in females $(p<0.001)$. Similarly, the correlation coefficient between NC and WC was 0.602 in males and 0.5 in females ( $p$ $<0.001$ ). Thus, NC was found to be independently related to central obesity. The ROC curves are presented in Figure 2 and 3. The area under the curve for neck circumference was statistically significant $(p=0.005)$. For overweight, the neck circumference showed the largest AUC in male which were 0.965 vs 0.848 in females $(p<0.001)$. The AUC for neck

Table 3. Cut off values of Neck Circumference (in $\mathrm{cm}$ ) for determining the individuals with central obesity and overweight based on ROC analysis

\begin{tabular}{|c|c|c|c|c|c|c|}
\hline \multirow{2}{*}{ Characteristics } & \multicolumn{3}{|c|}{$\begin{array}{l}\text { Male } \\
(n=45)\end{array}$} & \multicolumn{3}{|c|}{$\begin{array}{l}\text { Female } \\
(n=55)\end{array}$} \\
\hline & $\begin{array}{l}\text { Cut-off of } \\
\mathrm{NC} \text { in } \mathrm{cm}\end{array}$ & $\begin{array}{l}\text { Sensitivity } \\
(95 \% \mathrm{Cl})\end{array}$ & $\begin{array}{l}\text { Specificity } \\
(95 \% \mathrm{Cl})\end{array}$ & $\begin{array}{l}\text { Cut-off of } \\
\text { NC in cm }\end{array}$ & $\begin{array}{l}\text { Sensitivity } \\
(95 \% \mathrm{Cl})\end{array}$ & $\begin{array}{l}\text { Specificity } \\
(95 \% \mathrm{Cl})\end{array}$ \\
\hline $\begin{array}{l}\text { Overweight } \\
\text { (BMI 23-24.9 Kg/m2) }\end{array}$ & 35.55 & 97.3 & 87.5 & 35.2 & 81 & 70.6 \\
\hline $\begin{array}{l}\text { Central obesity } \\
\text { (WC in Men } \geq 90 \mathrm{~cm} \text { and } \\
\text { Women } \geq 80 \mathrm{~cm} \text { ) }\end{array}$ & 36.75 & 78.9 & 76.9 & 34.75 & 79.5 & 54.5 \\
\hline
\end{tabular}



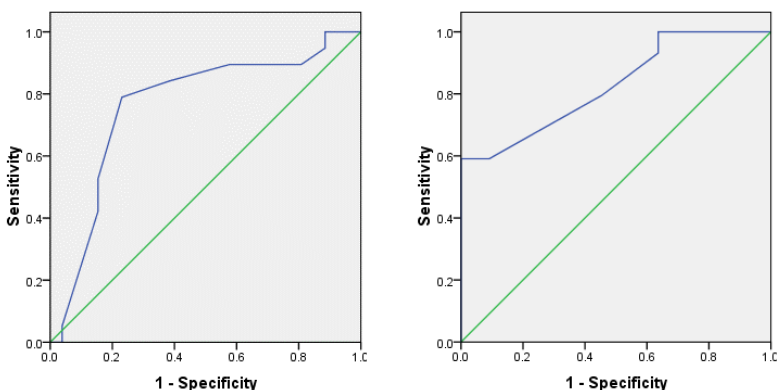

Fig 2a. Receiver operating curve for NC versus central obesity in males Fig $2 b$. Receiver operating curve for NC versus central obesity in females

circumference was quite large for central obesity too. It was 0.763 in male vs 0.826 in female $(p=$ 0.003). The cut off value of neck circumference for overweight was $35.55 \mathrm{~cm}$ in males vs $35.2 \mathrm{~cm}$ in females (Table 3). The cut off neck circumference value for central obesity was $36.75 \mathrm{~cm}$ in males vs $34.75 \mathrm{~cm}$ in females.

\section{DISCUSSION}

From this study, we were able to find a relationship of NC to WC and BMI, thereby to central obesity and overweight respectively. Moreover, the cut off values of neck circumference for each of the aforementioned conditions were determined in a small cohort of Nepalese population.

The study showed that the best cut off values of NC for determining overweight are $\geq 35.55 \mathrm{~cm}$ and $\geq 35.2 \mathrm{~cm}$ in males and females respectively. The NC of $\geq 36.75 \mathrm{~cm}$ and $\geq 34.75 \mathrm{~cm}$ in males and females respectively were determined to be the best cut off values for central obesity. This observation was similar to the study by Guang-ran, et al. ${ }^{12}$ There was a similar trend of higher cut offs in males compared to females. Mozaffer et al. in his study has found NC $>35.5 \mathrm{~cm}$ in males and $>32 \mathrm{~cm}$ in females as cut off for overweight/obesity in Pakistani young adults. ${ }^{13}$ This study had only included young students of 1820 years of age and it was not conducted in diabetic patients. Those could be the reasons for lower cut off values. However, the study has concluded that NC could be a potentially useful initial screening tool for overweight/obesity.

The cut off values of neck circumference is different in different populations as suggested by studies in China, Brazil, Pakistan and various other parts of the world. It could also be due to different diagnostic standards for overweight and obesity. The prevalence of overweight and obesity is higher in diabetic patients compared to the general population. Therefore, the other reason for this discrepancy could be because some studies were done in diabetic subjects while the others were done in general population.
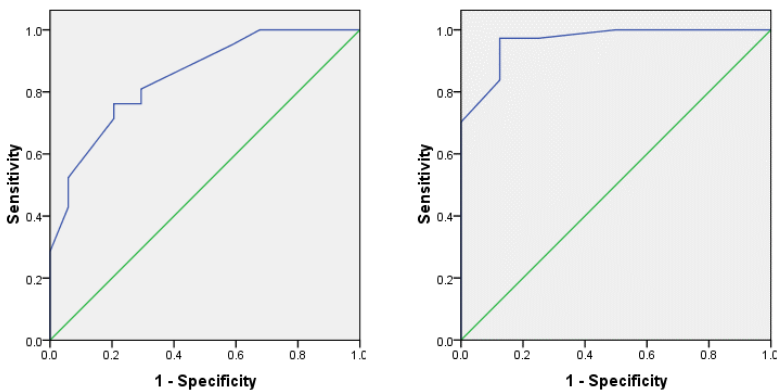

Fig 3a. Receiver operating curve for NC versus overweight in males Fig 3b. Receiver operating curve for NC versus overweight in females

In our study, central obesity was present in $63 \%$ of cases. This is in accordance with the previous study done in Turkey where abdominal obesity was 66\%. A study conducted in Pakistan showed that one out of every four persons is overweight or obese in general population. The prevalence is higher in diabetic population. Nepal is facing the challenges of unhealthy lifestyle among its citizens leading to obesity due to rapid urbanization. Migration to urban areas during the time of Nepalese civil war (1996-2006) also may have contributed to unhealthy lifestyle due to changes in the dietary habit.

In the Framingham Heart Study, Preis et al. found that NC was positively associated with risk of type 2 diabetes. After further adjustments for $\mathrm{BMI}$ and WC, NC remained associated with type 2 diabetes. ${ }^{14,15}$ In a Turkish Adult Cohort Study, results were obtained from middle-aged and elderly individuals. ${ }^{4}$ The results confirmed that NC was significantly correlated with all outcomes of cardiometabolic risks in both male and female.

Similar study by Aswathappa et al. in 2013 entitled neck circumference as an anthropometric measure of obesity in diabetics. The results showed positive correlation of NC, BMI and central obesity. The NC in diabetics was significantly higher than in nondiabetics ( $p<0.001$ ). According to the study, NC $>36 \mathrm{~cm}$ in non-diabetics and $>37 \mathrm{~cm}$ in diabetics was the best cutoff value to determine subjects with central obesity. ${ }^{16}$

Typically, BMI is used to measure the degree of adiposity. BMI correlates with the proportion of fat in the body and mass of the body fat. BMI can also be used to guide the choice of therapy. However, it is important to note that, BMI may not be an accurate measure of overweight in a very muscular person. It may be overestimated in such cases.

Neck circumference (NC) is considered a simple, newer, practical and efficient anthropometric measurement by large number of studies. It has been identified as an index of central obesity and a promising potential predictor for cardio-metabolic syndrome. NC might denote fat deposition at an ectopic site such as observed in fatty liver. 
WC measurements are easily affected by food intake and starvation, respiratory movement and clothing. These problems can be avoided in the $\mathrm{NC}$ measurement. Therefore, NC is a more reliable anthropometric measure to indicate central obesity.

South Asians are found to develop obesity related complications at a lower threshold for BMI and lower WC than people of European origin according to epidemiological evidence. For that reason, World Health Organization (WHO) and International Diabetes Federation (IDF) guidelines use different thresholds for defining overweight and obesity in South Asians which is outlined in Table 1.

The 2007 Non-Communicable Diseases Risk Factor Survey estimated average male waist circumference in Nepal at $74.9 \mathrm{~cm}$ (95\% confidence interval: 73.7-76.1 cm); in females, it was 70.3 $\mathrm{cm}$ (68.9-71.8 cm). ${ }^{17}$ The study did not consider the neck circumference. In our study, average male and female waist circumference were found to be 89.38 and $84.33 \mathrm{~cm}$. This discrepancy could be due to several reasons. Firstly, our study was conducted only in patients with established type 2 diabetes mellitus rather than in general population. Secondly, people's eating habits have changed over these several years which may be another contributing factor for overweight and obesity. The 2005 Dharan study reported a prevalence of both general and central obesity in 1,000 males. ${ }^{17}$ High levels of central obesity (between 40\% and 60\%) was reported to occur across different demographic groups which matches with our study.

This study has certain limitations. First and foremost, it was conducted in a diabetic population in a tertiary center. So the results cannot be generalized to the whole Nepalese population. Similar study should be conducted in general population that is community based, to see whether the positive association of neck circumference to central obesity holds true. Secondly, the sample size of the study was small. Therefore, the cut off values of neck circumference should be tested by further studies with larger sample size. Finally, neck circumference is a proxy for upper body subcutaneous fat but the quantification of fat by radiographic measures was not done.

\section{CONCLUSION}

Neck circumference (NC) was found to be strongly associated with central obesity and overweight. NC of $\geq 36.75 \mathrm{~cm}$ in males and $\geq 34.75 \mathrm{~cm}$ in females respectively were determined to be the best cut off values for central obesity. It is an uncomplicated and inexpensive test that can be performed in any office setting (outpatient department) with a tape measure. Thus, NC can be used as a simple and alternative screening tool to identify such patients with type 2 diabetes in a resource limited setting.

\section{CONFLICT OF INTEREST}

None declared.

\section{REFERENCES}

1. Obesity and overweight [Internet]. [cited 2020 May 7]. Available from: https://www.who.int/news-room/fact-sheets/detail/obesityand-overweight

2. Ben-Noun LL, Sohar E, Laor A. Neck circumference as a simple screening measure for identifying overweight and obese patients. Obes Res. 2001;9(8):470-477.

3. Shuster A, Patlas M, Pinthus JH, et al. The clinical importance of visceral adiposity: A critical review of methods for visceral adipose tissue analysis. Br J Radiol. 2012;85(1009):1-10.

4. Onat $A$, Hergenç $G$, Yüksel $H$, et al. Neck circumference as a measure of central obesity: Associations with metabolic syndrome and obstructive sleep apnea syndrome beyond waist circumference. Clin Nutr. 2009;28(1):46-51.

5. Misra A, Khurana L. Obesity-related non-communicable diseases: South Asians vs White Caucasians. Int J Obes (Lond). 2011;35(2):167-187.

6. Misra A, Chowbey P, Makkar BM, et al. Consensus statement for diagnosis of obesity, abdominal obesity and the metabolic syndrome for Asian Indians and recommendations for physical activity, medical and surgical management. J Assoc Physicians India. 2009;57:163-170.

7. Grundy SM, Brewer HB, Cleeman Jl, et al. Definition of Metabolic Syndrome: Report of the National Heart, Lung, and Blood Institute/ American Heart Association Conference on Scientific Issues Related to Definition. Circulation. 2004;109(3):433-438.

8. Grundy SM, Cleeman JI, Daniels SR, et al. Diagnosis and Management of the Metabolic Syndrome. Circulation. 2005 Oct 25;112(17):e297.

9. Einhorn D, Reaven GM, Cobin RH, et al. American College of Endocrinology position statement on the insulin resistance syndrome. Endocr Pract. 2003;9(3):237-252.

10. International Diabetes Federation (IDF). Worldwide Definition of the Metabolic Syndrome. Epidemiolgy Prev. 2006;

11. National Cholesterol Education Program. Third report of the expert panel on detection, evaluation and treatment of high blood cholesterol in adults - Adult Treatment Panel III. National Institutes of Health. 2002.

12. Yang GR, Yuan SY, Fu HJ, et al. Neck circumference positively related with central obesity, overweight, and metabolic syndrome in Chinese subjects with type 2 diabetes: Beijing community diabetes study 4. Diabetes Care. 2010;33(11):2465-7.

13. Hingorjo MR, Qureshi MA, Mehdi A. Neck circumference as a useful marker of obesity: A comparison with body mass index and waist circumference. J Pak Med Assoc. 2012;62(1):36-40.

14. Preis SR, Massaro JM, Hoffmann U, et al. Neck circumference as a novel measure of cardiometabolic risk: The framingham heart study. J Clin Endocrinol Metab. 2010;95(8):3701-10.

15. Preis SR, Pencina MJ, D'Agostino RB, et al. Neck circumference and the development of cardiovascular disease risk factors in the Framingham heart study. Diabetes Care. 2013 Jan;36(1):e3.

16. Aswathappa J, Garg S, Kutty K, et al. Neck circumference as an anthropometric measure of obesity in diabetics. N Am J Med Sci. 2013;5(1):28-31.

17. Vaidya A, Pokharel PK, Nagesh S, et al. Association of obesity and physical activity in adult males of Dharan, Nepal. Kathmandu Univ Med J. 2006;4(2):192-197. 